\title{
Histone deacetylase inhibitors providing an epigenetic treatment in cancer
}

\author{
Tuğçe Cinek ${ }^{1,2}$ (1), Nilgün Karalı (1) \\ 'Istanbul University, Institute of Health Sciences, Department of Pharmaceutical Chemistry, Istanbul, Turkey \\ 2Istanbul University, Faculty of Pharmacy, Department of Pharmaceutical Chemistry, Istanbul, Turkey
}

ORCID IDs of the authors: T.C. 0000-0001-5625-0189; N.K. 0000-0002-6916-122X

Cite this article as: Cinek, T., \& Karali, N. (2021). Histone deacetylase inhibitors providing an epigenetic treatment in cancer. istanbul Journal of Pharmacy, 51(2), 283-290.

\begin{abstract}
Cancer is among the leading causes of death worldwide and is therefore one of the diseases in which there have been major medical advances and which is the focus of researchers. Drugs used in cancer treatment affect rapidly proliferating normal cells as well as cancer cells. In recent years, targeted therapy has been provided by identifying specific pathways in cancer cells. Epigenetic mechanisms are among the targeted therapies in cancer treatment. Epigenetic regulators ensure the continuity of the normal process by inducing epigenetic changes through epigenetic mechanisms such as DNA methylation, histone post-translational modifications, and non-coding RNA regulation. Histone deacetylases (HDACs), which are involved in transcription-independent events such as DNA repair and mitosis, are enzymes that remove acetyl groups attached to the lysine residue in the amino terminal tails of histones. Histone deacetylase inhibitors (HDACls) that provide epigenetic treatment of cancer, which play a key role in the balance between acetylation and deacetylation of histone, have been extensively studied by researchers. Today, there are four HDACIs on the market approved by the FDA (Food and Drug Administration) and combinations of these drugs with agents that show anticancer activity by different mechanisms are being studied. Promising results have been obtained from these combinations, and further studies are ongoing on hybrid derivatives of certain $\mathrm{HDACls}$ in various stages.
\end{abstract}

Keywords: Cancer, epigenetic mechanisms, histone deacetylase, histone deacetylase inhibitors

\section{INTRODUCTION}

Epigenetics is the study of inheritable changes in gene expression or phenotype that do not result from changes in the DNA sequence (Dupont, Armant, \& Brenner, 2009). It has also been expressed as a bridge between phenotype and genotype (Korkmaz et al., 2011). These changes are called epigenetic changes and are crucial to the normal development processes of cells. Epigenetic regulators ensure the continuity of the normal process by inducing epigenetic changes through epigenetic mechanisms such as DNA methylation, histone post-translational modifications, and non-coding RNA regulation (Cao \& Yan, 2020; Handy, Castro, \& Loscalzo, 2011; İzmirli, 2013; Küçükoğlu, 2013). The presence of an abnormal epigenetic regulation in these epigenetic mechanisms causes many diseases such as cancer, autoimmune disorders, neurological diseases (Parkinson, Alzheimer, schizophrenia), inflammation, and metabolic disorders (Arrowsmith, Bountra, Fish, Lee, \& Schapira, 2012; Moosavi \& Ardekani, 2016). Therefore these mechanisms are therapeutic targets for researchers.

Post-translational modification is an important process in which certain groups such as acetyl and phosphate are transferred between proteins. These modifications include acetylation, phosphorylation, glycosylation, hydroxylation. Binding or separation of groups such as acetyl, hydroxyl, or phosphate to proteins affects cellular processes such as cell division, chromatin modification,

Address for Correspondence:

Tuğçe CiNEK, e-mail: tugcecinek@gmail.com

This work is licensed under a Creative Commons Attribution 4.0 International License.
Submitted: 28.03 .2021

Revision Requested: 25.05 .2021

Last Revision Received: 26.05.2021

Accepted: 27.05.2021

Published Online: 01.07 .2021 
gene silencing, protein-protein interactions, DNA replication, and apoptosis (Hitosugi \& Chen, 2014; Karve \& Cheema, 2011; Shukla \&Tekwani, 2020). Histones examples of such proteins that undergo post translational modification in this way. As a result of acetylation, which is one of the post-translational modifications of histones, the chromatin structure changes and plays an important role in gene expression (Eckschlager, Plch, Stiborova, \& Hrabeta, 2017), and HDACs are enzymes that remove acetyl groups attached to the lysine residue in the amino terminal tails of histones. As a result of the electrostatic interaction between the negatively charged DNA and the positively charged histone in the deacetylated state, a more compact chromatin structure is formed. In this state, the chromatin structure is "closed" and transcription is suppressed. When the histone is acetylated, the "open" chromatin structure is observed and transcription is active. Acetylation of histones and the level of transcription is controlled by the HAT (histone acetylase) and HDAC enzymes and is reversible (Gürel, Feyda Nursal, \& Yigit, 2016; Meng et al., 2016). Additionally, HDACs are involved in transcription-independent events such as DNA repair and mitosis, and histones are not their only substrates. It deacetylates non-histone proteins involved in various physiological events such as cell proliferation and gene expression. It causes the accumulation of deacetylated forms of non-histone protein substrates such as DNA repair enzymes, inflammation mediators and transcription factors. For this reason, HDACs have been seen as drug targets due to their active role in transcription and transcription independent physiological events. Treatment with HDACls result in acetylation of substrates, which is associated with transcriptional activation, but this treatment induces transcriptional suppressors, resulting in gene suppression. HDACls are used in cancer treatment by causing apoptosis, growth arrest, inhibiting migration, invasion and angiogenesis. In addition, normal cells are more resistant to treatment with HDACls than transformed cells and HDACls have low toxicity in cancer treatment. This is one of the reasons why they are seen as drug targets (Martínez-lglesias et al., 2008; Xu, Parmigiani, \& Marks, 2007). HDACs can also influence transcription-independent events such as mitosis or deoxyribonucleic acid (DNA). The chromatin structure that changes with the addition and removal of the acetyl group to the chromatin structure via HAT and HDAC enzymes is shown in Figure 1 (Zuma \& De Souza, 2018).

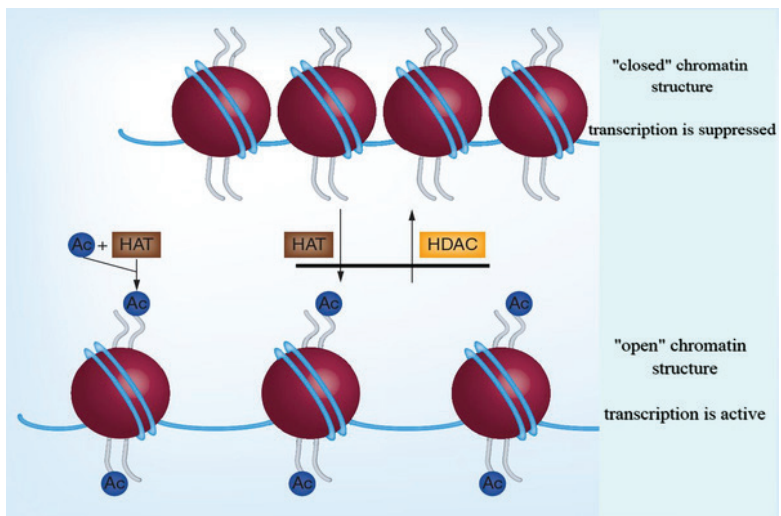

Figure 1. The "closed" and "open" chromatin structure formed by the transfer of the acetyl group via HAT and HDAC enzymes (Zuma \& De Souza, 2018).

\section{Structural components of typical histone deacetylase inhibitors}

HDACls consist of four main structural components: the zinc binding region, the linker, the surface recognition region (cap group) and the connecting unit between linker and surface recognition region. The zinc binding zone is located at the bottom of the $11 \mathrm{~A}^{\circ}$ long enzyme pocket, and polar functional groups in the molecule chelate with the zinc ion therein. These functional groups can be hydroxamic acid, the first derivative, or nonhydroxamic acid derivatives, thiol, sulfone, carboxylic acid, boronic acid, trifluoromethylketone, and alpha substituted ketoamide.

The linker of hydrophobic character occupies the $11 \mathrm{~A}^{\circ}$ long channel. The groups here can be linear, cyclic, saturated or unsaturated, and the residues in the channel change in different HDAC isoforms. This difference enables more selective inhibitors to be developed. The surface recognition region has groups to interact with residues at the entrance of the enzyme channel. These groups are aromatic heteroaromatic groups that are hydrophobic in nature. Many studies consider the connecting unit (or polar linker) to be within the surface recognition region and some as a separate pharmacophore (Bertrand, 2010; Ganai, 2019; Pontiki \& Hadjipavlou-Litina, 2012).

As a result of the research, an internal cavity with a hydrophobic character and a length of $14 \mathrm{~A}^{\circ}$ was discovered right next to the internal cavity. Since the size of this cavity differs between isoforms, it is seen as a target to achieve a selective effect (Pontiki \& Hadjipavlou-Litina, 2012). In Figure 2, the enzyme sites where the inhibitors bind are observed in the $X$-ray crystal of bacterial histone deacetylase-like protein and Trichostatin A (TSA) (Finnin et al., 1999).

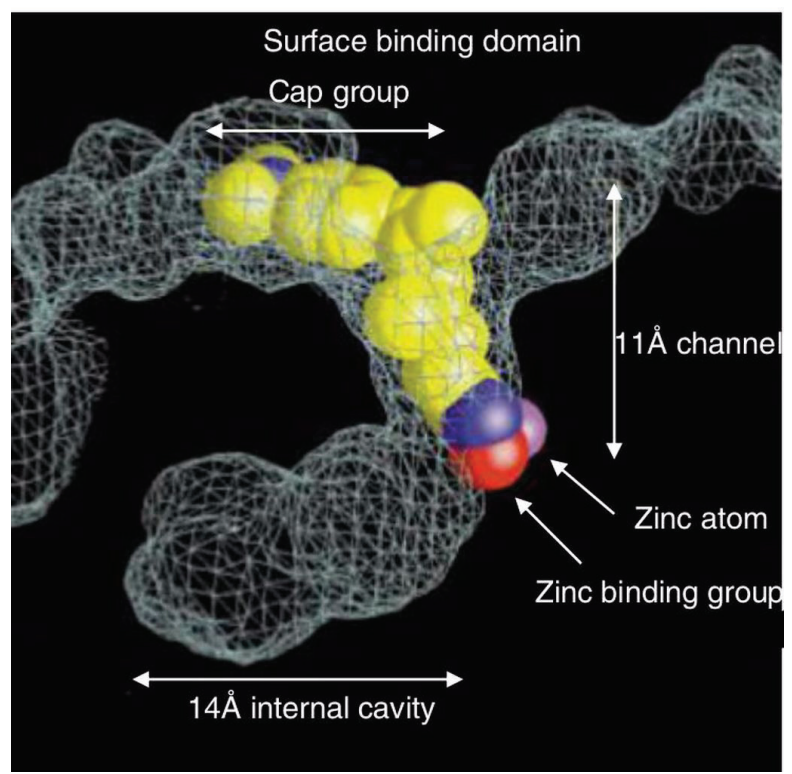

Figure 2. X-ray crystal of TSA in the active site of bacterial histone deacetylase-like protein (Finnin et al., 1999).

\section{FDA approved histone deacetylase inhibitors}

HDACls have gained importance in cancer treatment due to their low toxicity and cancer cells being more sensitive to these inhibitors than normal cells (Martínez-lglesias et al., 2008). 
In treatment with conventional chemotherapeutic agents, changes occur in the tumor cell through epigenetic mechanisms and as a result, resistance to treatment begins (Fardi, Solali, \& Farshdousti Hagh, 2018). Because of their effect on one of the epigenetic mechanisms, the use of HDACls is promising as monotherapy in cancer treatment or in combination with traditional chemotherapeutic agents. Combination therapies of HDACls with radiation therapy, kinase inhibitors (sorafenib and imatinib), and topoisomerases are in clinical trials. HDACls, which are considered as chemosensitizers in combined therapy, show a synergistic effect by increasing the effect of other agents in combined therapy. In combination therapy with HDACls, it has been shown that the response to traditional chemotherapeutic agents is increased, as well as the decrease in resistance to these agents (Fardi et al., 2018; Küçükoğlu, 2013; Martínez-Iglesias et al., 2008; Suraweera, O’Byrne, \& Richard, 2018).

\section{Vorinostat (SAHA)}

Vorinostat (suberoylanilide hydroxamic acid), also known as SAHA, was approved by the FDA in 2006 for the treatment of cutaneous T-cell lymphoma (CTCL) patients and is an orally used HDACl. As emphasized by the name SAHA, the drug is a derivative of hydroxamic acid. (Cappellacci, Perinelli, Maggi, Grifantini, \& Petrelli, 2018; Mann, Johnson, Cohen, Justice, \& Pazdur, 2007). The effect of DMSO (dimethyl sulfoxide) on murine erythroleukemia cells led to the discovery of HMBA (hexamethylene bisacetamide). A series of bishydroxamic acids derivatives have been synthesized due to HMBA's inhibitory effect on cell growth in altered cells. The best activity among them was observed with vorinostat. The similarity of vorinostat to TSA allowed the discovery of its HDACl effect (Marks \& Breslow, 2007). The chemical structures of vorinostat, HMBA, DMSO and TSA are shown in Figure 3.

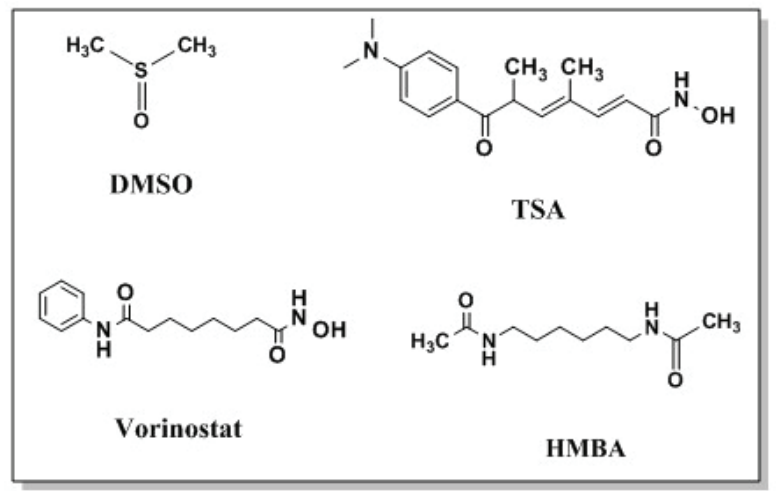

Figure 3. The chemical structures of DMSO (dimethyl sulfoxide), TSA (Trichostatin A), HMBA (hexamethylene bisacetamide) and vorinostat.

Vorinostat has an inhibitory effect on HDAC I and II enzymes at nanomolar levels (Marks \& Dokmanovic, 2005). The compound, which binds to the zinc ion in the catalytic region of the enzyme, acts as an inhibitor in this way and shows an anticancer effect by preventing the deacetylation of histone protein like other HDACls (Yoo \& Jones, 2006).

Patients with nonsmall cell lung cancer (NSCLC) and hepatocellular carcinoma (HCC) do not respond to treatment with a single therapy with tyrosine kinase inhibitors due to the development of resistance over time. The combination of vorinostat with the epidermal growth factor receptor (EGFR) tyrosine kinase inhibitor (TKI) gefitinib or a multi-target kinase inhibitor sorafenib was investigated in vitro and in vivo study. Vorinostat has been found to have the potential to restore the reduced sensitivity of the cancerous cell due to the development of resistance and to lower the concentration required for cell death (Jeannot et al., 2016). Moreover, hybrid molecules such as CUDC-101 have been developed as a result of the synergistic effect of HDACls and EGFRIs together and the sensitizing effect of HDACls. CUDC-101 is a multi-target inhibitor that inhibits not only EGFR and HDAC but also human epidermal growth factor 2 (HER2) (Lai et al., 2010; Parag-sharma et al., 2021). The chemical structure of CUDC-101 is shown in Figure 4.

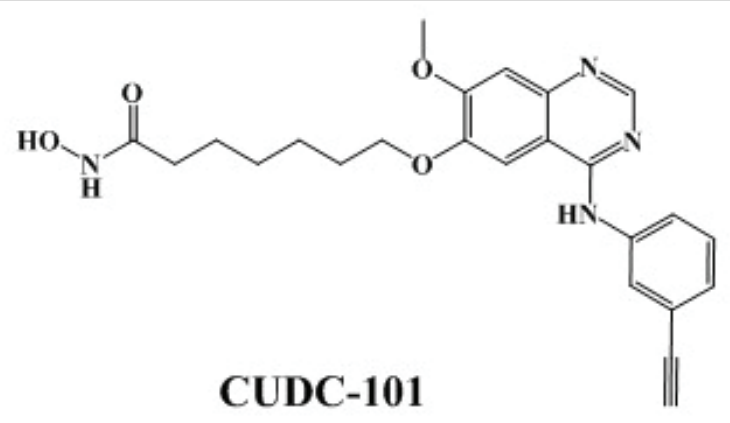

Figure 4. The chemical structure of CUDC-101.

Combined treatment of vorinostat with belinostat and dexamethasone against multiple myeloma is new because vorinostat, which is HDACl, and belinostat, which is a proteasome inhibitor, show anticancer effects through different mechanisms. This triple combination therapy against multiple myeloma has yielded good results in the phase II trial. However, a toleration problem has been observed. Research suggests that more specific HDACls with different toxicity profiles may provide more tolerance (Brown et al., 2021).

Various effects of vorinostat on cervical cancer have been demonstrated, such as inhibition of proliferation, migration and invasion. Natural killer (NK) cells are part of the immune response against tumor cells. Increased MICA (major histocompatibility class I related chain A) in cervical cancer cells affects the ability of NK cells to recognize and kill them. MICA induced by vorinostat increases the ability of NK cells to kill and recognize cervical cancer cells, so vorinostat is considered as an immunotherapeutic enhancer (Xia, He, Cai, \& Liang, 2020).

\section{Panobinostat (FARYDAK, LBH589)}

Panobinostat is an orally used inhibitory drug that targets HDAC I, Ila, IIb and IV enzymes (Park, Terranova-barberio, Zhong, Thomas, \& Munster, 2017; Raedler, 2016). The drug was approved by the FDA in 2015 to treat people with multiple myeloma who have previously had at least 2 standard regimens. This standard regimen includes bortezomib and immunomodulatory drugs. Panobinostat is effective at the nanomolar 
level. The drug, which reaches its maximum concentration approximately 2 hours after oral ingestion, is eliminated in the liver by the CYP3A4 enzyme (Moore, 2016; Raedler, 2016). Like other histone deacetylase inhibitors, it removes acetyl groups attached to lysine residues in histone or nonhistone proteins. Removal of the acetyl group from the lysine residue leads to relaxation of the chromatin structure and, consequently, transcriptional activation occurs. As a result of the accumulation of these acetylated proteins, apoptosis and cell cycle arrest are observed in abnormal cells (Raedler, 2016). The chemical structure of panobinostat is shown in Figure 5.

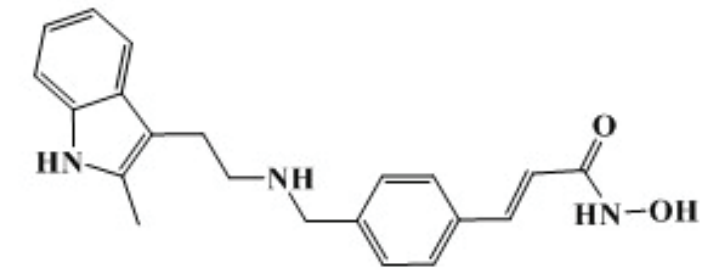

Panobinostat

Figure 5. The chemical structure of panobinostat.

It has been suggested that HDACls have a therapeutic effect against glioblastoma multiforme (GBM) using various mechanisms such as inhibition of angiogenesis or cell cycle arrest. Thereupon, the anti-GBM efficacy of the combined treatment of HDACI panobinostat and dual PI3K / mTOR inhibitor BEZ235 was investigated. This binary combination has been shown to synergistically induce apoptosis, inhibit cell growth and proliferation in GBM cells. In addition, this combination shows these effects through various mechanisms such as increasing caspase 3/7 activity (Meng et al., 2019). The chemical structure of BEZ235 is shown in Figure 6.

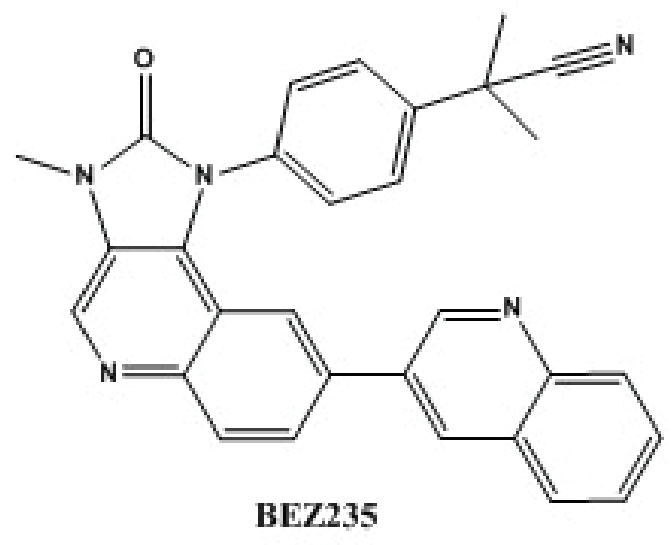

Figure 6. The chemical structure of BEZ235.

Various studies have shown that some HDACl drugs, such as vorinostat and panobinostat, have sensitizing effects against ovarian cancer. These HDACls block the removal of acetyl groups in a number of histone and nonhistone proteins as mentioned earlier. The increased acetylation level of heat shock protein 90 (HSP90) by panobinostat leads to a decrease in chaperone activity. Furthermore, resistance to drugs that cause DNA damage such as cisplatin develops. Priming with HDACls such as panobinostat has been shown to sensitize ovarian cancer cells to HSP90 inhibitors and cisplatin, but triple therapy with $\mathrm{HDACl}, \mathrm{HSP} 90$ inhibitor and cisplatin has no advantage (Moita et al., 2020; Ozaki et al., 2008).

In a phase I study conducted with 12 menopausal metastatic breast cancer patients, it was concluded that the combination therapy of panobinostat with an aromatase inhibitor letrozole is an effective potential therapy, especially in patients who have been evaluated to have chemotherapy and endocrine resistance (Tan et al., 2016). The chemical structure of letrozole is shown in Figure 7.

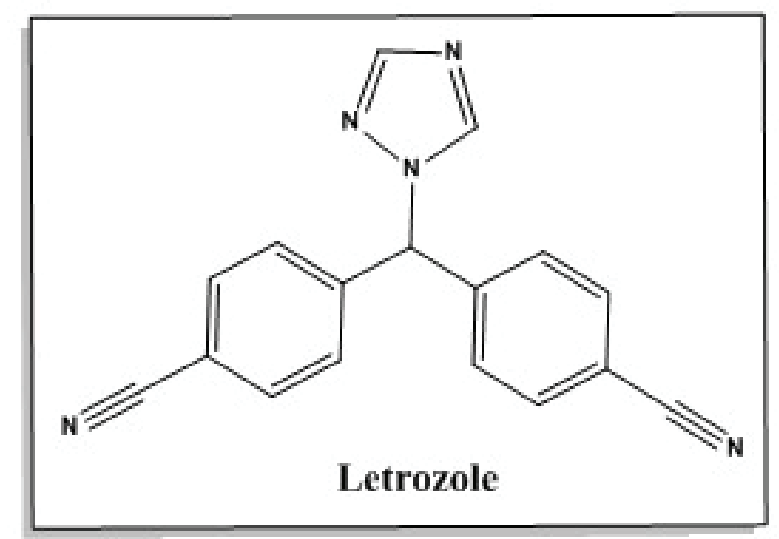

Figure 7. The chemical structure of letrozole.

\section{Belinostat (PXD-101)}

Belinostat is an inhibitor of HDAC I, II and IV enzyme isoforms, approved by the FDA in 2014. FDA approval was based on the results of a trial conducted with 120 patients and the drug has been approved for the treatment of patients with relapsed or refractory peripheral T-cell lymphoma (Campbell \& Thomas, 2017; Poole, 2014). The chemical structure of belinostat is shown in Figure 8.

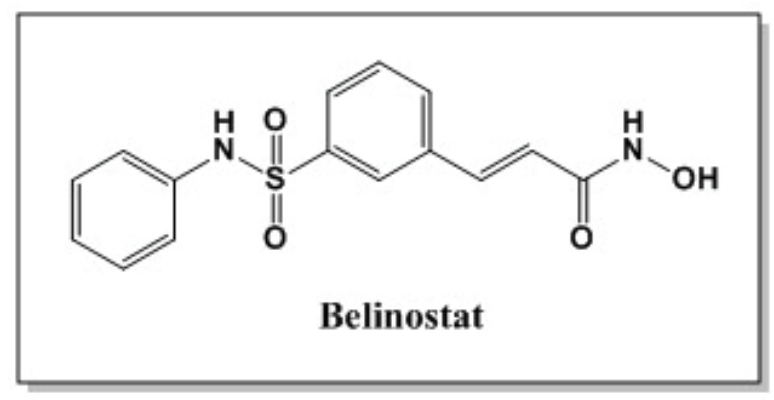

Figure 8. Chemical structure of belinostat.

In a phase II study of belinostat in women with epithelial ovarian cancer (EOC), belinostat was tested and found to be well tolerated in platinum-resistant EOC patients. However, it was concluded that belinostat as a single agent did not show 
enough efficacy for further research (Mackay et al., 2010). In another study, a synergistic effect of belinostat with paclitaxel and carboplatin on ovarian cancer was observed, whereupon a phase $1 \mathrm{~b} / 2$ clinical trial was conducted to further investigate the synergistic effect of belinostat with carboplatin and paclitaxel in female patients with EOC. In this phase 1b/2 trial, women with ovarian cancer had previously received platinum therapy, and patients were evaluated as platinum sensitive or platinum-resistant according to the time elapsed after the platinum treatment. In this trial, it was shown that the overall response rate (ORR) to treatment was $43 \%$ and which was due to the heterogeneous distribution of the patients compared to the previous platinum treatment. It was not possible to evaluate the benefit of belinostat over paclitaxel and carboplatin combination therapy. Therefore, it was decided that a study in which patients were classified according to their sensitivity to platinum was required (Dizon et al., 2012).

\section{Romidepsin (Depsipeptide or FK228)}

Romidepsin is a naturally occurring compound that was first isolated in 1994 from the Gram negative bacterium Chromobacterium violaceum. The compound was evaluated as a novel antitumor antibiotic in 1994 and received FDA approval in 2011 for the treatment of peripheral T-cell lymphomas (PTCLs) (Barbarotta \& Hurley, 2015; Shigematsu, Ueda, Takase \& Tanaka, 1994; Ueda et al., 1994). Romidepsin is a prodrug that becomes active as a result of the reduction of the intramolecular disulfide bond. The thiol group formed by reduction coordinates the $\mathrm{Zn}^{2+}$ ion of the enzyme (Cappellacci et al., 2018; Porter \& Christianson, 2019). The chemical structure of romidepsin is shown in Figure 9.

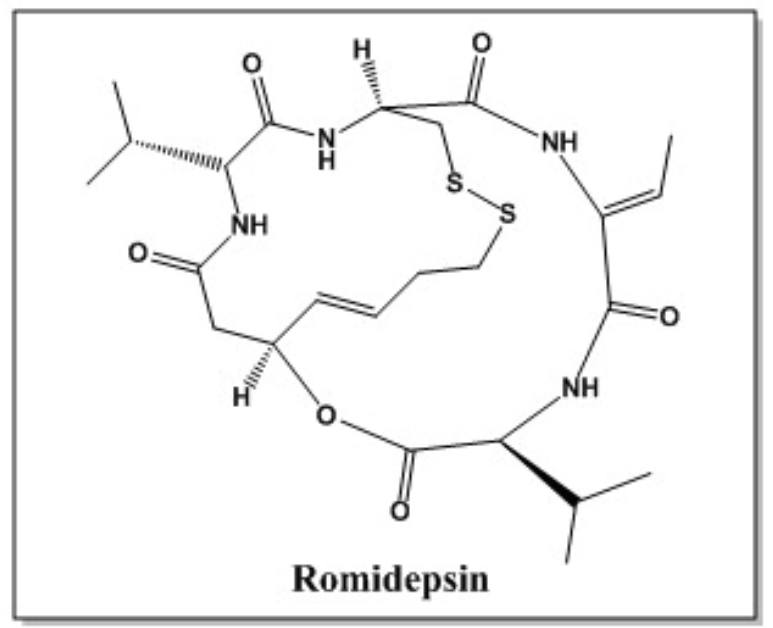

Figure 9. Chemical structure of romidepsin.

Combinations of romidepsin with various drugs such as ifosfamide, carboplatin and etoposide on PTCL were found to be more effective than romidepsin alone, but it was observed that the toxicity was higher in these combinations. For this purpose, due to the low toxicity of bendamustine, the combination of this drug with romidepsin was tried in patients with relapsed/ refractory T-cell lymphoma who had previously received treatment. Romidepsin/bendamustine combination was observed to have a greater effect on patients with relapsed/ refractory
T-cell lymphoma than either drug alone. In the study, it was emphasized that the combination showed acceptable toxicity, but this clinical data belongs to a small patient group and this combination deserves further research (Nachmias et al., 2019).

Pirfenidone and nintedanib are two drugs approved for the treatment of idiopathic pulmonary fibrosis (IPF), a progressive disease. However, these drugs have undesirable side effects, and no treatment for IPF has stopped the decline in lung function. After demonstrating in a phase II study that some HDACls such as vorinostat and panobinostat have antifibrotic properties and romidepsin has selectivity against lung cancer, the antifibrotic effects of romidepsin was investigated in vivo and in vitro. As a result of the research, the antiproliferative and antifibrotic effects of romidepsin were found to be potent and it was stated that these effects supported the evaluation of romidepsin as a new treatment for IPF in clinical research (Conforti et al., 2017).

\section{Future Directions}

Epigenetic therapy has proven its importance and success for cancer treatment. For this reason, in order to develop more effective and specific molecules and to reduce side effects, it is important to understand both the structures of enzyme isoforms and their differences from each other and the mechanism of action of these epigenetic drugs. In this way, isoformspecific molecules can be designed and more biomarkers can be discovered by understanding their mechanism of action. Thus, a mechanism-based treatment approach is provided (Küçükoğlu, 2013; Shukla \& Tekwani, 2020).

Another important issue is the epigenetic profiles of the patients. The epigenetic and genetic profile of each patient is unique. The epigenetic and genetic profile of the patient should be known in order to obtain an optimum response in these combined treatments with epigenetic drugs. Otherwise, no response may be obtained from the treatment. In the future, patients can be screened with more precise methods and classified according to their genetic structure. With all these considerations, a personal, unique treatment should be provided for each patient (specific drug should be selected) in order to achieve optimal effect as well as reduce side effects and toxicity (Fardi et al., 2018; Martínez-Iglesias et al., 2008; Schwartsmann et al., 2000).

At this point, biomarkers should be determined. HDAC levels in the patient can be used as a biomarker and have prognostic importance. In this way, patient subgroups that will benefit from HDACls can be determined and specific treatment can be provided for the patient (Stimson \& La Thangue, 2009).

Another major promising topic is hybrid HDACls. There is a paradigm shift from "one drug one target" theory to "multitarget drug". Combination of HDACls with other anticancer drugs is being investigated in preclinical and clinical studies and many combinations are known to have synergistic effects. For this purpose, hybrid molecules have been designed to reduce both side effects and drug-drug interactions, and also to achieve this synergistic effect with a single molecule. Hybrid drugs designed with the protection of HDACls and other 


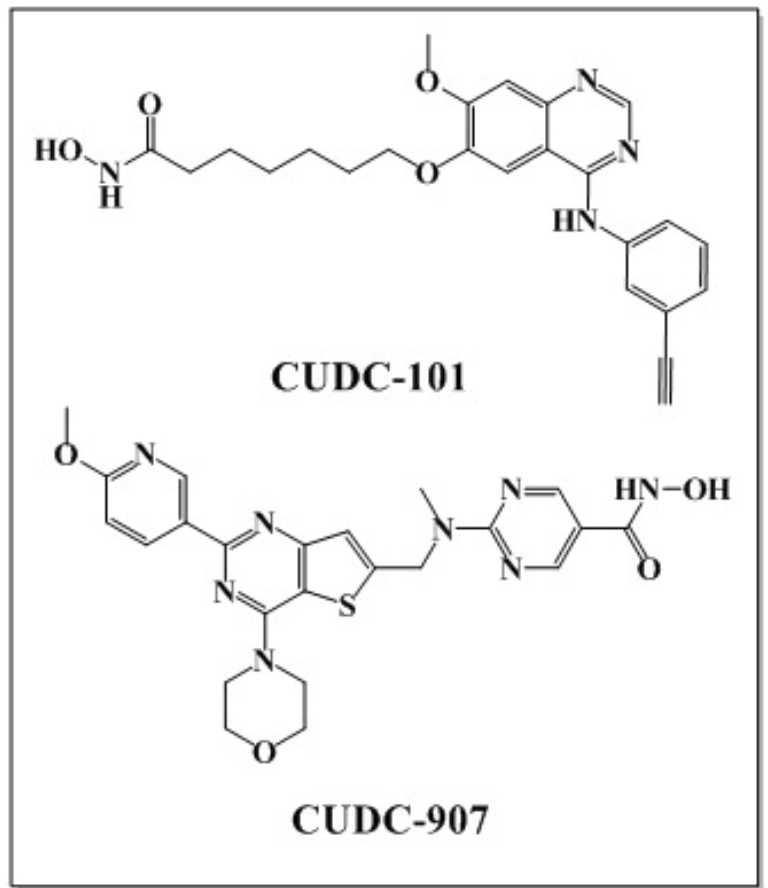

Figure 10. Chemical structures of CUDC-101 and CUDC-907.

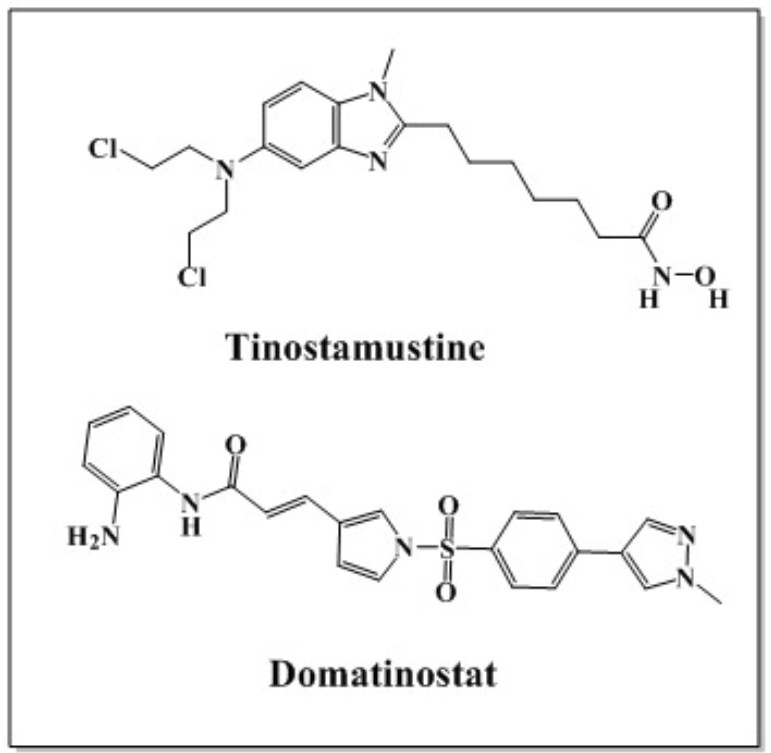

Figure 11. Chemical structures of tinostamustine and domatinostat.

anticancer drug's pharmacophore groups that interact with the enzyme can simultaneously inhibit various cancer-related targets or pathways. Hybrid molecules of HDACls have been designed with many drug groups such as topoisomerase, protein kinase, proteasome, phosphodiesterase type 5 (PDE5) and bromodomain containing 4 (BRD4) inhibitors. Of these, CUDC101 (a molecule mentioned earlier) and fimepinostat (CUDC907) are hybrid molecules in various clinical trial phases for the treatment of different types of cancer (Bass et al., 2021; Vaidya et al., 2021). Fimepinostat (CUDC-907), a dual inhibitor of HDAC and PI3K enzymes, has been shown to have more tumor growth inhibiting and pro-apoptotic activity in various cancer lines than single targeted agents that inhibit these enzymes (Younes et al., 2016). The chemical structures of CUDC-101 and CUDC-907 are shown in Figure 10.

Domatinostat is a hybrid molecule that targets both HDAC and LSD1, which was investigated in the phase I trial for the treatment of patients with hematological malignancies and demonstrated good tolerability and efficacy in this study (von Tresckow et al., 2019; Wobser et al., 2019). The chemical structures of tinostamustine and domatinostat are shown in Figure 11.

\section{CONCLUSION}

HDACls are a promising class of anticancer drugs that has caught the attention of researchers. Many studies have shown that epigenetic changes play an important role in cancer development, tumorigenesis or resistance to the anticancer drug used. There are currently four FDA-approved HDACls, although their effects against solid tumors as a monotherapy are limited. Belinostat, vorinostat, panobinostat, and romidepsin are approved for the treatment of patients with peripheral and/ or cutaneous T-cell lymphoma and multiple myeloma. In addition, the effects of these drugs in combination with antitumor drugs that affect different pathways such as protein kinases, topoisomerases, proteasome inhibitors or their effects with radiation therapy have been investigated in various clinical studies. Studies have shown the important effects of HDACls, such as regaining reduced sensitivity with the development of resistance to these drugs and reducing the dose required for treatment. Although HDACls are successful in combination therapy, a new approach is to rationally design hybrid molecules to minimize drug interactions and side effects. Phase studies of some hybrid molecules targeting both the HDAC enzyme and another cancer pathway are ongoing. With the discovery of specific effective and multi-targeted new drugs, it will be possible to reduce side effects and increase efficiency in cancer treatment.

Peer-review: Externally peer-reviewed.

Author Contributions: Conception/Design of Study-T.C.; Data Acquisition- T.C.; Data Analysis/Interpretation- T.C.; Drafting Manuscript- T.C.; Critical Revision of Manuscript-T.C., L.N.K.; Final Approval and Accountability-T.C., L.N.K.

Conflict of Interest: The authors have no conflict of interest to declare.

Financial Disclosure: Authors declared no financial support.

\section{REFERENCES}

- $\quad$ Arrowsmith, C. H., Bountra, C., Fish, P. V., Lee, K., \& Schapira, M. (2012). Epigenetic protein families: A new frontier for drug discovery. Nature Reviews Drug Discovery, 11, 384-400. https://doi. org/10.1038/nrd3674

- Barbarotta, L., \& Hurley, K. (2015). Romidepsin for the treatment of peripheral T-cell lymphoma. Expert Opinion on Investigational Drugs, 24(7), 965-979.

- $\quad$ Bass, A. K. A., El-Zoghbi, M. S., Nageeb, E. S. M., Mohamed, M. F. A., Badr, M., \& Abuo-Rahma, G. E. D. A. (2021). Comprehensive review for anticancer hybridized multitargeting HDAC inhibitors. European Journal of Medicinal Chemistry, 209, 112904. https://doi. org/10.1016/j.ejmech.2020.112904 
- $\quad$ Bertrand, P. (2010). Inside HDAC with HDAC inhibitors. European Journal of Medicinal Chemistry, 45, 2095-2116. https://doi. org/10.1016/j.ejmech.2010.02.030

- Brown, S., Pawlyn, C., Tillotson, A., Sherratt, D., Flanagan, L., Low, E., ... Phase, E. (2021). Original study combination therapy in relapsed myeloma: Results of the phase 2 MUK four trial. Clinical Lymphoma, Myeloma and Leukemia, 21(3), 154-161. https://doi. org/10.1016/j.clml.2020.11.019

- Campbell, P., \& Thomas, C. M. (2017). Belinostat for the treatment of relapsed or refractory peripheral T-cell lymphoma. Journal of Oncology Pharmacy Practice, 23(2), 143-147. https://doi. org/10.1177/1078155216634178

- Cao, J., \& Yan, Q. (2020). Cancer epigenetics, tumor immunity, and immunotherapy. Trends in Cancer, 6(7), 580-592. https://doi. org/10.1016/j.trecan.2020.02.003

- Cappellacci, L., Perinelli, D. R., Maggi, F., Grifantini, M., \& Petrelli, R. (2018). Recent progress in histone deacetylase inhibitors as anticancer agents. Current Medicinal Chemistry, 27(15), 2449-2493. https://doi.org/10.2174/0929867325666181016163110

- Conforti, F., Davies, E. R., Calderwood, C. J., Thatcher, T. H., Jones, M. G., Smart, D. E., ... Davies, D. E. (2017). The histone deacetylase inhibitor, romidepsin, as a potential treatment for pulmonary fibrosis. Oncotarget, 8(30), 48737-48754. https://doi.org/10.18632/ oncotarget.17114

- Dizon, D. S., Damstrup, L., Finkler, N. J., Lassen, U., Celano, P., Glasspool, R., ... Penson, R. T. (2012). Phase II activity of belinostat (PXD-101), carboplatin, and paclitaxel in women with previously treated ovarian cancer. International Journal of Gynecological Cancer, 22(6), 979-986. https://doi.org/10.1097/ IGC.0b013e31825736fd

- Dupont, C., Armant, D. R., \& Brenner, C. A. (2009). Epigenetics: definition, mechanisms and clinical perspective. Seminars in Reproductive, 27(5), 351-357. https://doi.org/10.1055/s-0029-1237423.

- Eckschlager, T., Plch, J., Stiborova, M., \& Hrabeta, J. (2017). Histone deacetylase inhibitors as anticancer drugs. International Journal of Molecular Sciences, 18, 1414-1439. https://doi.org/10.3390/ ijms18071414

- Fardi, M., Solali, S., \& Farshdousti Hagh, M. (2018). Epigenetic mechanisms as a new approach in cancer treatment: An updated review. Genes and Diseases, 5, 304-311. https://doi.org/10.1016/j. gendis.2018.06.003

- $\quad$ Finnin, M. S., Donigian, J. R., Cohen, A., Richon, V. M., Rifkind, R. A., Marks, P. A., ... Pavletich, N. P. (1999). Structures of a histone deacetylase homologue bound to the TSA and SAHA inhibitors. Nature, 401, 188-193. https://doi.org/10.1038/43710

- Ganai, S. A. (2019). Different groups of HDAC inhibitors based on various classifications. Histone Deacetylase Inhibitors - Epidrugs for Neurological Disorders (pp. 33-38). Springer Singapore. https:// doi.org/10.1007/978-981-13-8019-8_5

- $\quad$ Gürel, Ç., Feyda Nursal, A., \& Yigit, S. (2016). Epigenetik ve kanser [Epigenetics and cancer]. Turkiye Klinikleri Radiation Oncology Special Topics, 2(1), 45-51. Retrieved from https://www.researchgate.net/publication/309357812

- Handy, D. E., Castro, R., \& Loscalzo, J. (2011). Epigenetic modifications: basic mechanisms and role in cardiovascular disease. Circulation, 123(19), 2145-2156. https://doi.org/10.1161/CIRCULATIONAHA.110.956839

- Hitosugi, T., \& Chen, J. (2014). Post-translational modifications and the warburg effect. Oncogene, 33, 4279-4285. https://doi. org/10.1038/onc.2013.406

- İmirli, M. (2013). Epigenetik mekanizmalar ve kanser tedavisinde epigenetik yaklaşımlar. Van Tip Dergisi, 20(1), 48-51.
Jeannot, V., Busser, B., Vanwonterghem, L., Michallet, S., Ferroudj, S., Cokol, M., ... Hurbin, A. (2016). Synergistic activity of vorinostat combined with gefitinib but not with sorafenib in mutant KRAS human non-small cell lung cancers and hepatocarcinoma. OncoTargets and Therapy, 9, 6843-6855. https://doi.org/10.2147/ OTT.S117743

- $\quad$ Karve, T. M., \& Cheema, A. K. (2011). Small changes huge impact: The role of protein posttranslational modifications in cellular homeostasis and disease. Journal of Amino Acids, 2011, 1-13. https:// doi.org/10.4061/2011/207691

- Korkmaz, A., Manchester, L., Topal, T., Ma, S., Tan, D., \& Reiter, R. (2011). Epigenetic mechanisms in human physiology and diseases. Journal of Experimental and Integrative Medicine, 1(3), 139-147. https://doi.org/10.5455/jeim.060611.rw.003

- Küçükoğlu, K. (2013). Histonların asetilasyonu ve histon deasetilaz inhibitörleri [Acetylation of histones and histone deacetylase inhibitors: Review]. Journal of Literature Pharmacy Sciences, 2(2), 55-73. Retrieved from http://www.turkiyeklinikleri.com/journal/ eczacilik-bilimleri-dergisi/2146-944X/

- $\quad$ Lai, C., Bao, R., Tao, X., Wang, J., Atoyan, R., Qu, H., ... Qian, C. (2010). CUDC-101, a multitargeted inhibitor of histone deacetylase, epidermal growth factor receptor, and human epidermal growth factor receptor 2 , exerts potent anticancer activity. Cancer Research, 70(9), 3647-3657. https://doi.org/10.1158/0008-5472.CAN-09-3360 Mackay, H. J., Hirte, H., Colgan, T., Covens, A., MacAlpine, K., Grenci, P., ... Oza, A. M. (2010). Phase II trial of the histone deacetylase inhibitor belinostat in women with platinum resistant epithelial ovarian cancer and micropapillary (LMP) ovarian tumours. European Journal of Cancer, 46, 1573-1579. https://doi.org/10.1016/j. ejca.2010.02.047

Mann, B. S., Johnson, J. R., Cohen, M. H., Justice, R., \& Pazdur, R. (2007). FDA approval summary: vorinostat for treatment of advanced primary cutaneous T-cell lymphoma. The Oncologist, 12(10), 1247-1252. https://doi.org/10.1634/theoncologist.12-10-1247

Marks, P. A., \& Breslow, R. (2007). Dimethyl sulfoxide to vorinostat: Development of this histone deacetylase inhibitor as an anticancer drug. Nature Biotechnology, 25, 84-90. https://doi. org/10.1038/nbt1272

Marks, P. A., \& Dokmanovic, M. (2005). Histone deacetylase inhibitors: discovery and development as anticancer agents. Expert Opinion on Investigational Drugs, 14, 1497-1511. https://doi. org/10.1517/13543784.14.12.1497

- Martínez-lglesias, O., Ruiz-Llorente, L., Sánchez-Martínez, R., García, L., Zambrano, A., \& Aranda, A. (2008). Histone deacetylase inhibitors: Mechanism of action and therapeutic use in cancer. Clinical and Translational Oncology, 10(7), 395-398. https://doi. org/10.1007/s12094-008-0221-X

Meng, F., Wang, C., Wan, W., Lu, W., Lu, W., \& Luo, C. (2016). Discovery and development of small molecules targeting epigenetic enzymes with computational methods. In J. L. Medina-Franco (Eds.), Epi-Informatics: Discovery and Development of Small Molecule Epigenetic Drugs and Probes (pp. 75-112). Academic Press. https://doi.org/10.1016/B978-0-12-802808-7.00004-6

- Meng, W., Wang, B., Mao, W., Wang, J., Zhao, Y., \& Li, Q. (2019). Enhanced efficacy of histone deacetylase inhibitor panobinostat combined with dual PI3K / mTOR inhibitor BEZ235 against glioblastoma. Nagoya Journal of Medical Science, 81(1), 93-102. https://doi.org/10.18999/nagjms.81.1.93

Moita, A. J. R., Bandolik, J. J., Hansen, F. K., Kurz, T., Hamacher, A., \& Kassack, M. U. (2020). Priming with HDAC inhibitors sensitizes ovarian cancer cells to treatment with cisplatin and hsp90 inhibitors. International Journal of Molecular Sciences, 21(21), 1-22. https://doi.org/10.3390/ijms21218300 
- Moore, D. (2016). Panobinostat ( Farydak) a novel option for the treatment of relapsed or relapsed and refractory multiple myeloma. Pharmacy and Therapeutics, 41(5), 296-300.

- Moosavi, A., \& Ardekani, A. M. (2016). Role of epigenetics in biology and human diseases. Iranian Biomedical Journal, 20(5), 246258. https://doi.org/10.22045/ibj.2016.01

- Nachmias, B., Shaulov, A., Lavie, D., \& Goldschmidt, N., Gural, A., Saban, R., Lebel, E., \& Gatt, M. E. (2019). Romidepsin-bendamustine combination for relapsed/ refractory $T$ cell lymphoma. Acta Haematologica, 141, 216-221. https://doi.org/10.1159/000498905

- Ozaki, K. I., Kishikawa, F., Tanaka, M., Sakamoto, T., Tanimura, S., \& Kohno, M. (2008). Histone deacetylase inhibitors enhance the chemosensitivity of tumor cells with cross-resistance to a wide range of DNA-damaging drugs. Cancer Science, 99(2), 376-384. https://doi.org/10.1111/j.1349-7006.2007.00669.x

- Parag-sharma, K., Tasoulas, J., Musicant, A. M., Viesi, C. H., Zhu, Z., Twomey, C., ... Amelio, A. L. (2021). Synergistic efficacy of combined EGFR and HDAC inhibitors overcomes tolerance to EGFR monotherapy in salivary mucoepidermoid carcinoma. Oral Oncology, 115, 105166. https://doi.org/10.1016/j.oraloncology.2020.105166

- $\quad$ Park, J., Terranova-barberio, M., Zhong, A. Y., Thomas, S., \& Munster, P. N. (2017). Clinical applications of histone deacetylase inhibitors. In T. O. Tollefsbol (Eds.), Handbook of Epigenetics (Second Edi) (pp. 605-621). Academic Press. http://dx.doi.org/10.1016/B978-0-12805388-1.00040-7

- Pontiki, E., \& Hadjipavlou-Litina, D. (2012). Histone deacetylase inhibitors (HDACls). structure-activity relationships: History and new QSAR perspectives. Medicinal Research Reviews, 32(1), 1-165.

- Poole, R. M. (2014). Belinostat: First global approval. Drugs, 74(13), 1543-1554. https://doi.org/10.1007/s40265-014-0275-8

- Porter, N. J., \& Christianson, D. W. (2019). Structure, mechanism, and inhibition of the zinc-dependent histone deacetylases. Current Opinion in Structural Biology, 59, 9-18. https://doi. org/10.1016/j.sbi.2019.01.004

- Raedler, B. L. A. (2016). Farydak (Panobinostat): First HDAC inhibitor approved for patients with relapsed multiple myeloma. American Health \& Drug Benefits, 9, 84-87.

- Schwartsmann, G., Schunemann. H., Gorini, C. N. F., Filho Ferreira, A. F., Garbino, C., Sabini, G., Muse, I., DiLeone, L., \& Mans, D. R. (2000). A phase I trial of cisplatin plus decitabine, a new DNAhypomethylating agent, in patients with advanced solid tumors and a follow-up early phase II evaluation in patients with inoperable non-small cell lung cancer. Investigational New Drugs, 18, 83-91. https://doi.org/10.1023/A

- $\quad$ Shigematsu, N., Ueda, H., Takase, S., Tanaka, H., Yamamoto, K., \& Tada, T. (1994). FR901228, a novel antitumor bicyclic depsipeptide produced by chromobacterium violaceum no. 968. II. structure determination. The Journal of Antibiotics, 47(3), 311-314. https:// doi.org/10.7164/antibiotics.47.311

- Shukla, S., \& Tekwani, B. L. (2020). Histone deacetylases inhibitors in neurodegenerative diseases, neuroprotection and neuronal differentiation. Frontiers in Pharmacology, 11. https://doi. org/10.3389/fphar.2020.00537
Stimson, L., \& La Thangue, N. B. (2009). Biomarkers for predicting clinical responses to HDAC inhibitors. Cancer Letters, 280, 177183. https://doi.org/10.1016/j.canlet.2009.03.016

Suraweera, A., O'Byrne, K. J., \& Richard, D. J. (2018). Combination therapy with histone deacetylase inhibitors (HDACi) for the treatment of cancer: achieving the full therapeutic potential of HDACi. Frontiers in Oncology, 8. https://doi.org/10.3389/fonc.2018.00092 Tan, W. W., Allred, J. B., Moreno-Aspitia, A., Northfelt, D. W., Ingle, J. N., Goetz, M. P., \& Perez, E. A. (2016). Phase I study of panobinostat (LBH589) and letrozole in postmenopausal metastatic breast cancer patients. Clinical Breast Cancer, 16(2), 82-86. https://doi. org/10.1016/j.clbc.2015.11.003

- $\quad$ Ueda, H., Nakajıma, H., Horı, Y., Fujıta, T., Nıshımura, M., Goro, T., \& Okuhara, M. (1994). FR901228, a novel antitumor bicyclic depsipeptide produced by chromobacterium violaceum No. 968: I. taxonomy, fermentation, isolation, physico-chemical and biological properties, and antitumor activity. The Journal of Antibiotics, 47(3), 301-310.

- Vaidya, G. N., Rana, P., Venkatesh, A., Chatterjee, D. R., Contractor, D., Satpute, D. P., ... Kumar, D. (2021). Paradigm shift of "classical" HDAC inhibitors to "hybrid" HDAC inhibitors in therapeutic interventions. European Journal of Medicinal Chemistry, 209, 112844. https://doi.org/10.1016/j.ejmech.2020.112844

- von Tresckow, B., Sayehli, C., Aulitzky, W. E., Goebeler, M. E., Schwab, M., Braz, E., ... Engert, A. (2019). Phase I study of domatinostat (4SC-202), a class I histone deacetylase inhibitor in patients with advanced hematological malignancies. European Journal of Haematology, 102(2), 163-173. https://doi.org/10.1111/ejh.13188 Wobser, M., Weber, A., Glunz, A., Tauch, S., Seitz, K., Butelmann, T., ... Houben, R. (2019). Elucidating the mechanism of action of domatinostat (4SC-202) in cutaneous T cell lymphoma cells. Journal of Hematology and Oncology, 12(1), 1-16. https://doi. org/10.1186/s13045-019-0719-4

- $\quad$ Xia, C., He, Z., Cai, Y., \& Liang, S. (2020). Vorinostat upregulates MICA via the PI3K / Akt pathway to enhance the ability of natural killer cells to kill tumor cells. European Journal of Pharmacology, 875(2019), 173057. https://doi.org/10.1016/j.ejphar.2020.173057

- $\quad$ Xu, W. S., Parmigiani, R. B., \& Marks, P. A. (2007). Histone deacetylase inhibitors: molecular mechanisms of action. Oncogene, 26, 5541-5552. https://doi.org/10.1038/sj.onc.1210620

- Yoo, C. B., \& Jones, P. A. (2006). Epigenetic therapy of cancer: past, present and future. Nature Reviews Drug Discovery, 5, 37-50. https://doi.org/10.1038/nrd1930

- Younes, A., Berdeja, J. G., Patel, M. R., Flinn, I., Gerecitano, J. F., Neelapu, S. S., ... Akins, A. (2016). Safety, tolerability, and preliminary activity of CUDC-907, a first-in-class, oral, dual inhibitor of HDAC and PI3K, in patients with relapsed or refractory lymphoma or multiple myeloma : an open-label, dose-escalation, phase 1 trial. Lancet Oncology, 2045(15), 1-10. https://doi.org/10.1016/ S1470-2045(15)00584-7

- Zuma, A. A., \& De Souza, W. (2018). Histone deacetylases as targets for antitrypanosomal drugs. Future Science OA, 4(8). https:// doi.org/10.4155/fsoa-2018-003 